\title{
Ras-Related GTP-Binding Protein D
}

National Cancer Institute

\section{Source}

National Cancer Institute. Ras-Related GTP-Binding Protein D. NCI Thesaurus. Code C137973.

Ras-related GT P-binding protein D (400 aa, $\sim 46 \mathrm{kDa})$ is encoded by the human RRAGD gene. This protein plays a role in both GTP-binding and lysosomal localization of mTOR complex 1 (mTORC1). 